\title{
Welfare consequences of request stops at transport services with low demand
}

\author{
Finn Jørgensen and Gisle Solvoll
}

\begin{abstract}
Background: Demand-responsive transport is an alternative to fixed-route, fixed-scheduled transport services in low-demand areas.

Objective: This paper discusses the welfare and distributional consequences of the implementation of request stops (RSs) on a scheduled fixed-stop transport service.

Method: The discussion is based on a general welfare model. The focus is on discussing how the magnitudes of the welfare effects on different groups of travellers are influenced by travel patterns and the characteristics of the travellers involved.

Results: The effects of implementing RSs are critically dependent on the booking procedure, the variation in demand throughout the day, and the travellers' time values per hour when on the mode and when arriving at the destinations before having any appointments. Moreover, the benefits for the operators and the authorities depend strongly on the risk profile in the tendering contract.
\end{abstract}

Keywords: Public transport, Rural areas, Request stops, Welfare consequences

\section{Introduction}

Changes in population density and settlement patterns, an ageing population, and increased car ownership have resulted in significant challenges for local public transport systems [11, 37]. These changes have particularly disfavoured conventional fixed-stop (FS) transport services in rural areas. Therefore, more demand-responsive transport (DRT) services have been established in low-demand areas $[1,7,20,22$, 33, 37]. There are different definitions of DRT services $[6,15,28]$. DRT services are usually considered 'intermediate' forms of transport, somewhere between public and individual transport solutions, that cover a wide range of transport services [21, 22].

The research on DRT services in rural areas has largely focused on system design, the efficiency and effectiveness of different means of organising the service, and technological issues regarding, for example, information systems, real-time information, telematics, and

* Correspondence: gisle.solvoll@nord.no

Business School, Nord University, NO-8049 Bodø, Norway intelligent transport systems (cf. the literature review in Section 2). Thus, the main research effort has focused on the operational and logistic challenges related to DRT services. Far less focus has been on the elaboration of the welfare implications of DRT services. Therefore, the aim of this article is to discuss the welfare and distributional consequences of DRT services in rural areas. We focus on transport services that Koffman [21] refers to as request-stop (RS) services, that is, a conventional fixed-route that also serves stops near the route in response to passengers' requests.

The forthcoming discussion is related to fast craft services, which are critical modes of transport along the Norwegian coastline. Many of these services have several ports of call, and some of the calls have only RSs due to the limited demand for trips. In this county where fast craft services are most important (Nordland), $41 \%$ of the ports of call have an RS, whereas $34 \%$ have an FS. The remaining $25 \%$ of ports of call have an RS and FS for which service is dependent on the weekday, Jørgensen, Mathisen, and Solvoll [18]. The situation in other coastal
Springer Open (c) The Author(s). 2020 Open Access This article is licensed under a Creative Commons Attribution 4.0 International License, which permits use, sharing, adaptation, distribution and reproduction in any medium or format, as long as you give appropriate credit to the original author(s) and the source, provide a link to the Creative Commons licence, and indicate if changes were made. The images or other third party material in this article are included in the article's Creative Commons licence, unless indicated otherwise in a credit line to the material. If material is not included in the article's Creative Commons licence and your intended use is not permitted by statutory regulation or exceeds the permitted use, you will need to obtain permission directly from the copyright holder. To view a copy of this licence, visit http://creativecommons.org/licenses/by/4.0/. 
counties in Norway is similar; the use of RSs on these transport services is significant and increases as the population in rural areas decreases, implying reduced demand for transport services. Although we focus on the mode of transport where RSs are most common, the forthcoming discussion is also relevant to other transport means such as ferries and buses.

We organise the article as follows. Section 2 is a brief literature review. In Section 3, the theoretical approach regarding the distributional and welfare consequences of implementing an RS at a call instead of an FS is presented. Section 4 is a thorough discussion of the magnitudes of the welfare effects on the involved groups. Section 5 provides an example of the application of the welfare model. Last, in Section 6, we summarise the main findings and offer concluding remarks.

\section{Literature review}

A significant research effort has been made to investigate the design and classification of the types of DRT services. Mageean and Nelson [22] divide DRT route concepts into three main groups: (i) semi-fixed routes (i.e. services that can deviate to predefined and nonpredefined stop points with fixed intermediate stop points), (ii) flexible routes (i.e. services that can deviate to predefined and non-predefined stop points with no fixed intermediate stop points), and (iii) virtual flexible routes (i.e. services that stop at non-predefined stop points with no fixed intermediate stop points).

Koffman [21] operates with as many as six types of flexible transit services: (i) 'route deviation' (i.e. a regular scheduled service that can deviate to serve demandresponsive requests within a zone around the path), (ii) 'point deviation' [i.e. similar to (i) but with a possibility to serve a limited number of stops within the zone without any regular path between the stops], (iii) 'demand responsive connector' (i.e. vehicles that operate in a demand-responsive mode within a zone with scheduled transfer points that connect with a fixed-route network), (iv) 'request stop' (i.e. a conventional fixed-route that also serves stops near the route in response to passengers' requests), (v) 'flexible-route segments' (i.e. a conventional fixed-route that switches to a demandresponsive operation for a limited portion of the route), and (vi) 'zone route' (i.e. vehicles operate in a demandresponsive mode along a corridor with established departure and arrival times at one or more endpoints).

Because demand for public transport in rural areas is low, the research has focused on designing flexible-route systems with low system costs [26] where the users' benefits are considered in different manners, for example, by the performance measure of the transit system [30], service punctuality [5], or response speed to requests [4].
The use of mobile technology and real-time information has also been a focus in the literature. Papangelis, Nelson, Sripada, and Beecroft [27] investigate the effects of mobile real-time passenger information (RTPI) on passengers in rural areas. They find that RTPI has positive effects on the passengers' perceived control over their journey and their perceived waiting time. The basis for a study by Watkins, Ferris, Rutherford, and Layton [38] is that an inexpensive means to combat the perception of unreliability from a user perspective is real-time transit information. A critical finding is that mobile realtime information reduces customers' perceived waiting time and actual waiting time.

Regarding welfare consideration, Gomes, de Sousa, and Dias [10] discuss DRT services in relation to the problem of sustainability and social inclusion challenges in transport. They indicate that to prevent the failure of DRT projects, it is critical to solve the underlying model in an efficient manner and understand how different manners of operating the service affect customers and operators. Saeed and Kurauchi [33] discuss enhancing transit services in rural areas with complex road network topographies where fixed services are less available or are cost ineffective. They discuss services that minimise the sum of operators' costs and users' costs. Kim and Schonfeld [20] use an algorithm to maximise welfare (consumer surplus + producer surplus) with elastic demand relations for fixed-route and flexible-route services in systems with multiple dissimilar regions and periods. In general, conventional services are increasingly preferable to flexible-route services as demand densities and route lengths increase. Furth and Muller [9] investigate the problem of holding buses to scheduled departure times at timepoints. Based on an objective to minimise the sum of operating costs and user costs, they demonstrate that a timepoint's optimal strictness (probability of holding) increases with the demand for boardings at the timepoint. However, the effect diminishes as stops become farther from the start of the route, and welfare benefits compared with using a uniform percentage of slack across the route may be small.

Additionally, a substantial amount of literature has evaluated the types of DRT services. By using 20 years of data, Rodier, Johnston, and Shabazian [31] employ a travel demand model to simulate the travel, emissions, and welfare effects of advanced public transport system (APTS) technologies in the Sacramento, California, region (in the United States) for 2015. Their simulations show that the APTS technology generated an economic benefit when total operating costs were included. Diana, Quadrifoglio, and Pronello [8] assess how the organisational form of the transit system may affect the environment in terms of distance travelled between a traditional fixed-route and a DRT service. The results indicate that 
DRT services minimise emissions for high-quality service level and low-demand density scenarios.

Mageean and Nelson [22] introduce the concept of telematics-based DRT services and focus on DRT technologies and the positive influence this technology has on DRT services. Brake, Nelson, and Wright [2] emphasise that (at least) four areas related to DRT require substantial attention: legal and regulatory issues, technological issues, service and system design issues, and the sustainability of the DRT service. They stress that as demand becomes marginal, more flexible transport solutions are required. The paper by Brake and Nelson [1] has a user perspective. Based on their case study of Northumberland, they state that rural public transport services will require wider area network planning, greater cooperation between service providers (e.g. in the form of partnerships), and improved understanding of passenger requirements. Mulley, Nelson, Teal, Wright, and Daniels [25] explore the extent to which barriers to the implementation of flexible transport services (FTS) identified in New South Wales, Australia, have been encountered and overcome in the United States and Europe. They state that transport service planners and providers can obtain greater use of FTS by sharing best practices and information on overcoming barriers to implementation.

Velaga, Nelson, Wright, and Farrington [35] explore the context of public transport provision in rural and remote areas. Experiences from selected case studies in Scotland confirm that FTS provides a critical contribution to the public transport system in such areas. Ryley, Stanley, Enoch, Zanni, and Quddus [32] investigate the sustainability credentials of DRT services using evidence from the United Kingdom. Of the DRT services investigated, those targeting airline or train passengers have potential. However, these services are in direct competition with cars; thus, their success depends on the cost and availability of parking spaces. Some of the DRT schemes explored fulfil social needs such as access to shopping facilities or hospitals, but the cost challenges are prohibitive.

Davison et al. [7] use a national survey of DRT providers in Great Britain to examine the design, performance, rationale, and likely futures of DRT schemes. Their findings suggest that increasing the role of stakeholders from the voluntary sector and the private sector results in greater use of smaller vehicles. Notably, cost and funding remain dominant concerns of DRT service providers. Wang et al. [37] investigate how individual-level factors influence the use of DRT systems in rural Lincolnshire, England. The analysis shows that people who are disabled, commuters, or residents of less densely populated areas are likely to travel more frequently by DRT.
Jain, Ronald, Thompson, and Winter [16] provide and evaluate a methodology to estimate the demand patterns in an area that wants to avoid ambivalent and expensive user-preference surveys in the design of a DRT service. They state that analysis of demographic and trip characteristics of the population can be used to predict the spatial demand pattern of a proposed transport service in a target city.

The literature review shows that the main research effort regarding DRT services has focused on the impact of IT-systems on the efficiency of such services and the importance of different means to organise the service administratively and operationally. Some research has also investigated the welfare economic impact of DRT. This body of research has focused on operational costs and user benefits. Notably, more principled discussions regarding welfare effects and the distributional impacts of DRT have received scant attention.

\section{Theoretical approach}

3.1 Welfare impacts of request stops - the illustrative example

We discuss consequences of RSs based on what Koffman [21] defines as a 'request stop' service. The welfare and distributional consequences are exemplified by a fast craft service connecting three settlements, each of which has a port (Fig. 1). Without much loss of generality, we highlight the main effects of RSs by focusing on the simplified situation where there is only one potential RS (port B) between two FSs (port $A$ and $C$ ). However, in Section 4.5, we mention the following problem: several RSs $\left(B_{1}, B_{2}, \ldots, B_{M}\right)$ might be between the FSs $\mathrm{A}$ and $\mathrm{C}$.

Initially, the fast craft service connects places A - B $\mathrm{C}$ on a regular basis, that is, all three places have an FS. The service provider receives subsidies from the transport authorities that are supposed to cover the gap between expected income and operating costs (net contract). Due to limited traffic to and from place B, located between place $A$ and place $C$, the transport authorities considered offering place B an RS instead of an FS. We assume that no minimum requirements for the number of travellers to/from place B are set to call it, and that the ticket price is unchanged. This situation could be regarded as a Dial-a-Ride Problem or an extended variant of a Vehicle Routing Problem [5]. However, in the case of a scheduled transport service, the sequence of the pick-up and delivery points is given.

\subsection{Impacts on the involved groups}

When place $B$ receives an RS instead of an FS, it is fruitful to specify the monetary effects $\left(W_{i}\right)$ for the following four groups. 


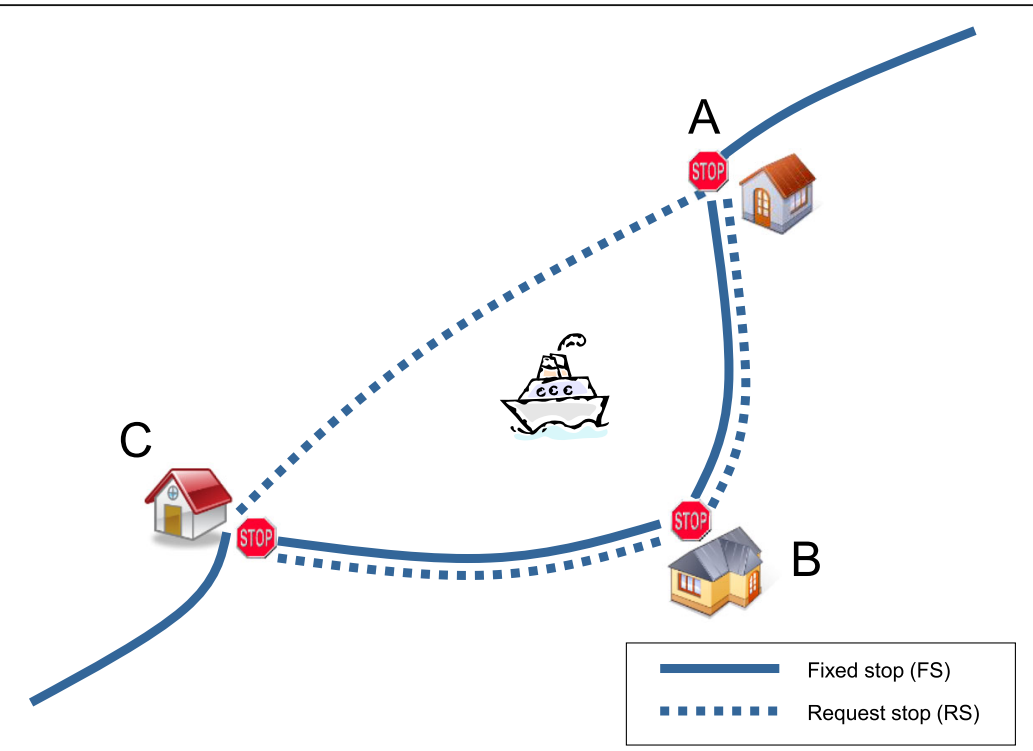

Fig. 1 Place B switches from a fixed stop to a request stop

- Impact on passengers travelling to/from place $B$ $\left(W_{B}\right) . W_{B}>0$ if the initiative is positive for the population at place $\mathrm{B}$, and $W_{B}<0$ if it is perceived as negative. We reasonably assume that a change from an FS to an RS is considered negative, implying that $W_{B}<0$. A monetary value for $W_{B}$ can be estimated by asking people at place $B$ about their willingness to pay to retain the FS.

- Impact on passengers travelling between $A$ and $C$ $\left(W_{A C}\right) \cdot W_{A C}>0$ if the initiative is advantageous for these travellers, and $W_{A C}<0$ otherwise. Because a change from an FS to an RS at place B sometimes leads to shorter travel times for travellers between place $\mathrm{A}$ and place $\mathrm{C}$, we reasonably assume that this situation is advantageous for them due to a reduction in on-board travel time costs. This implies $W_{A C}>0$.

- Impact on the service provider measured by changes in the operator's profits, including grants $\left(W_{S}\right)$. If the transition from an FS to an RS at place B increases (decreases) profits, $W_{S}>0(<0)$. The sign of $W_{S}$ depends on whether the cost reduction is greater or less than the income reduction.

- Impact on the transport authorities $\left(W_{T A}\right)$. If necessary, subsidies to the operator increase, an RS has a negative impact on the transport authorities' budget, implying that $W_{T A}<0$. If an RS reduces necessary grants, $W_{T A}>0$. The sign of $W_{T A}$ strongly depends on the risk profile in the contract between the authorities and the service provider.
In Section 4, we more thoroughly discuss the factors that affect the magnitudes of these effects, and in Section 5, we use a calculation example to exemplify the procedure for estimating the impacts on the different groups.

\subsection{Political priorities and welfare economic consequences}

The welfare economic consequences ( $W$ ) of implementing RS at place B can be written as follows:

$$
W=W_{B}+W_{A C}+W_{S}+(1+\gamma) \cdot W_{T A}
$$

where $\gamma$ is the shadow price of raising public funds. ${ }^{1}$ When aiming to maximise social welfare, place B should receive an RS if $W>0$. Consequently, the same weights are put on all four groups, and the decision is made based on the Kaldor-Hicks criterion; see, for example, Pindyck and Rubinfeld [29].

However, if regional policy goals that cause benefits and disadvantages for different groups are given different weights, the decision to implement an RS at place B can be made based on the sign of the following weighted $\operatorname{sum}\left(W^{*}\right)$ :

$$
\begin{aligned}
W^{*}= & W_{B}+w_{A C} \cdot W_{A C}+w_{S} \cdot W_{S}+w_{T A} \\
& \cdot(1+\gamma) \cdot W_{T A}
\end{aligned}
$$

where, $w_{A C}, w_{S}$, and $w_{T A}$ are the relative weights the

\footnotetext{
${ }^{1}$ Norwegian authorities recommend a value of $\gamma=0.20$ (Ministry of Finance, 2014).
} 
decision maker puts on the consequences for the travellers between $\mathrm{A}$ and $\mathrm{C}$, the profit for the service provider, and the transport authorities' budget, respectively, compared with the consequences for those living at place $\mathrm{B}$. When $w_{A C}, w_{S}$, and $w_{T A}<1$, the decision maker places the highest value on the welfare of travellers living at place B. If $W^{n \prime}>0 \quad(<0)$, the transport authorities will (will not) recommend that place B receives an RS. Different $w$-values can produce situations where $W$ and $W^{*}$ have different signs. If, for example, $W^{*}<0$ and $W>0$, place B will retain the FS, and the welfare loss of pursuing the politicians' priorities ${ }^{2}$ is $W$.

Notably, setting the $w_{A C}, w_{S}$, and $w_{T A}$ values is a pure political decision and founded on regional policy goals for settlement patterns. Jørgensen, Mathisen, and Larsen [17] use the Kaldor-Hicks criterion and observe that 21 of the 97 Norwegian ferry services in 2007 contributed negatively to social surplus. By estimating ferry users' welfare from these 21 services and the total costs of operating them, Jørgensen et al. [17] estimate the weights $w_{i}(i=1,2, \ldots, 21)$ the decision makers (politicians) have tacitly put on the welfare for these ferry users compared with the welfare to the greater society. Their analysis shows the threshold values of $w_{i}$, which indicates that it is desirable to maintain each of the socio-economically unprofitable services, which varied from approximately 1.1 to 4.0. As expected, the value of $w_{i}$ was highest for ferry services operating in areas that had a low population and little traffic. This finding signals that the greater society puts the highest weight on the welfare of the people who live in small places.

The fast craft boats and the ferries operate in more or less the same areas along the Norwegian coastline, and the places where RSs are most relevant are small places. Transferred to our model and Eq.(3.2), this suggests that $w_{B}>w_{A C}>w_{S}>w_{T A}$ but that the ratio, $\frac{w_{B}}{w_{A c}}$, can vary a lot depending on the number of people living in places $A$, $B$, and $C$.

\section{Results and discussion}

\subsection{Travellers to/from the place with request stop}

\subsubsection{General considerations}

The welfare consequences for this group of travellers are illustrated in Fig. 2. The relationship between the annual number of passengers $(X)$ travelling to/from place $\mathrm{B}$ and ticket price $(P)$ equals $D_{0}$ with an FS at place $\mathrm{B}$, and $D_{1}$

\footnotetext{
${ }^{2}$ Suppose $W^{n}=W_{B}+w\left[W_{A C}+W_{S}+(1+\gamma) W_{T A}\right]$, where $w$ is the equal weight put on all groups except those living at place B. $W_{B}<0$ and $W_{A C}, W_{S}$, and $W_{T A}>0$ if place $\mathrm{B}$ receives an RS. If an RS is implemented $W^{*}>0$, implying $\frac{W_{B}}{W_{A C}+W_{S}+(1+\gamma) W_{T A}}<w$. If, for example , $W_{B}=-100$ and $\left[W_{A C}+W_{S}+(1+\gamma) W_{T A}\right]=125$, an RS is implemented at place $\mathrm{B}$ if $w$ is higher than 0.80 , and the social benefits are 25 .
}

with an RS at place B. The change from an FS to an RS has thus caused a negative shift in the demand curve for trips to/from place $\mathrm{B}$. When the ticket price is $P_{0}$, regardless of whether place B has an FS, the number of trips declines from $X_{0}$ to $X_{1}$.

Figure 2 shows that the less negative the shift in the demand curve and the higher the ticket price $\left(P_{0}\right)$, the less negative the effect of an RS on travellers to/from place $B$. The effect is also less negative as the demand for trips to/from place B becomes more price elastic (the curves $D_{0}$ and $D_{1}$ become less steep). Moreover, the disadvantages will decrease with the number of travellers to/from place $B$, that is, the demand curve $\left(D_{0}\right)$ shifts to the left. Last, the pre-booking procedures for an $R S$ are critical.

The disadvantages decrease with shorter pre-booking times; thus, residents at place B do not have to make their travel decision long before the journey occurs. This finding more or less implies that spontaneous trips can also occur with an RS. We also reasonably assume that the more options an individual has to pre-book a trip (call), the fewer disadvantages will result from a change to an RS. If, for example, when a traveller can pre-book a call by either cell phone, SMS, email, or a 'reservation app', the disadvantages of an RS are small.

Despite today's communication technology, replacing an FS with an RS results in less flexibility in peoples' travel opportunities, especially for elderly members of the community unfamiliar with new gadgetry. The tourist industry also claims that an RS instead of an FS reduces the number of tourists because of their unfamiliarity with the booking rules. Some fast craft operators in Norway have recently sharpened the opportunities to book at short notice, which makes an RS worse for inhabitants at place B. Therefore, the pre-booking procedures result in some people either forgetting to book a call or booking too late. This finding implies that when switching from an FS to an RS, a negative shift in the demand curve can be expected (Fig. 2).

At least in Norway, most of the places where it is relevant to change boat services from FS to RS are located on islands or in small places with no road connections. Thus, boat service is the only transport option. In such cases, the demand curves $D_{0}$ and $D_{1}$ in Figure 2 are steep (price inelastic), and the negative shift in the demand curve from $D_{0}$ to $D_{1}$ is small but not negligible. The travel demand from tourists and leisure travel from the locals is sensitive to the booking system and the ticket price. The reduction in consumer surplus or welfare for those living at place $B$ is equal to the shaded area $W_{B}$ in Figure 2.

In the very few places where there are other transport options, the demand curves in Figure 2 are flatter (price 


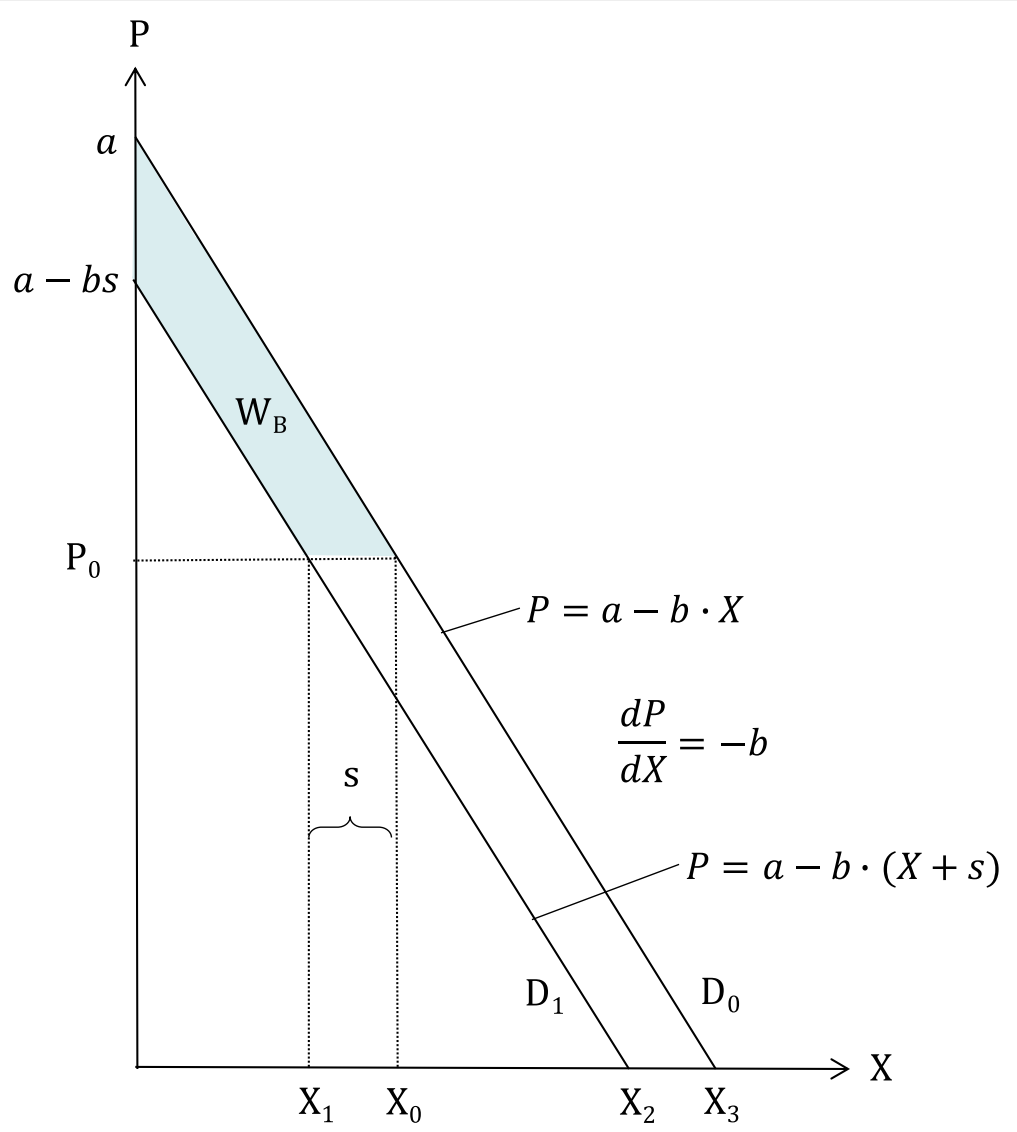

Fig. 2 Welfare consequences for the population at place $B$ because of a change from a fixed stop to a request stop

elastic). The more intense competition between the boat service and the other transport services to/from place B, the flatter the demand curves in Figure 2. Moreover, the negative shift in the demand curve from $D_{0}$ to $D_{1}$ will be greater. The reduction in the number of travellers that use the boat service that offers RS instead of FS will increase ( $s$ increases). If the number of travellers that use alternative transport services increases with $s^{*}$, total traffic to/from place B is reduced by $\left(s-s^{*}\right)$ when B gets RS instead of FS. This also indicates that the welfare loss for the residents at place $B$ is lower than the shaded area in Figure 2 because they can use other transport means. In our opinion, the value of $s^{*}$ is usually low, implying that $s$ and $W_{B}$ in Figure 2 are good estimates of the consequences of offering RS instead of FS.

The fast craft boats also take and bring goods to the RSs, and if the calls at these places are dependent on whether anyone wants to travel to or from them, RSs cause more uncertainty in the delivery of goods; notably, the latter can be a major drawback for the inhabitants.

The value of $W_{B}$ can also be inferred mathematically. Suppose the demand curves $D_{0}$ and $D_{1}$ on price forms are $P=a-b \cdot X$ and $P=a-b \cdot(X+s)$, respectively, where
$s=X_{0}-X_{1}$ is the horizontal negative shift in the demand curve. When $b$ increases, the trips become less price sensitive, implying that the demand curves in Figure 2 become steeper. The values of $X_{2}=\frac{a}{b}-s$ and $X_{3}=\frac{a}{b}$ indicate the market potential for traffic to/from place $B$ under RS and FS, respectively. When the ticket price is $P_{0}$, the consumer surplus for the population at place $\mathrm{B}$ becomes $\frac{1}{2} \cdot b \cdot X_{0}{ }^{2}$, and $\frac{1}{2} \cdot b \cdot\left(X_{0}-S\right)^{2}$ under an FS and an RS, respectively. The welfare changes from an RS for the population at place $\mathrm{B}, W_{B}$, thereby becomes:

$$
\begin{aligned}
W_{B} & =\frac{1}{2} \cdot b \cdot\left(X_{0}-s\right)^{2}-\frac{1}{2} \cdot b \cdot X_{0}^{2} \\
& =-b \cdot s \cdot\left(X_{0}-\frac{1}{2} \cdot s\right)
\end{aligned}
$$

When $b, s$, and $X_{0}$ increase, $W_{B}$ declines; thus, the consequences for the population at place $B$ become more negative. Hence, if $X_{0}$ and $\mathrm{b}$ is lower when there are transport options other than the RS service, $W_{B}$ decreases, implying $\mathrm{z}$ lower loss for the population at place $B$. 


\subsubsection{Empirical estimation of the consequences}

The magnitude of the change in welfare $\left(W_{B}\right)$ for the travellers to/from place B by introducing an RS can be quantified in two manners. First, when the RS scheme has been operating for some time, we can record the decrease in the number of passengers to/from place $\mathrm{B}$, that is, the difference $s=\left(X_{0}-X_{1}\right)$ in Eq. (4.1) and Figure 2. If we also know the price elasticity of demand when $P=P_{0}$ and $X=X_{0}$, the slope of the curve $D_{0}$ is determined (e.g. [29]). The aforementioned indicates that we know the values of $b, s$, and $X_{0}$ in Eq. (4.1), and $W_{B}$ can be calculated. Second, instead of using market data, we can estimate the disadvantages for these travellers from implementing an RS by asking a representative sample about their maximal willingness to pay to maintain an FS at place B. In this manner, $\left(W_{B}\right)$ can be inferred.

Each of the two methods has at least one weakness. The first method provides an imprecise estimate due to uncertain assumptions regarding the forms of the demand curves in Figure 2 and the point demand elasticity. Moreover, the decrease in traffic $(s)$ can only be calculated when an RS has been in operation for some time, leading to an uncertain estimate of $W_{B}$ beforehand. When the residents in place $B$ have transport options other than the boat, the second method can be better than using market data because these options are internalised in the respondents' answers. The better the other travel options, the lower the stated value of $W_{B}$. A weakness with it is, however, that it may provide an uncertain estimate because the respondents must make hypothetical choices and can give strategic answers [13]. The latter indicates that the respondents answer in a manner that they believe can promote their cause because they know they are not confronted with their answers because of anonymity [24]. Thus, such surveys may overestimate the disadvantages for the population of implementing an RS. Another method is to draw on experiences from other places that have implemented an RS. However, such analogous comparisons can be of limited value because circumstances vary widely by place [23].

\subsection{Travellers to/from the places with fixed stops 4.2.1 General considerations}

Suppose travel time between place A and place C (Figure 1) is $T_{1}$ hours when there is no call at place $B$ and $T_{0}$ hours when $\mathrm{B}$ is called. ${ }^{3}$ The reduction in travel time between place $\mathrm{A}$ and place $\mathrm{C}$ by omitting call at $\mathrm{B}(\Delta T)$ is

${ }^{3} \Delta T$ is the extra elapsed time and terminal time caused by calling place B.

$$
\Delta T=T_{0}-T_{1}
$$

Consequently, when the time value for a representative traveller is $k_{0}$, his/her reduction in time costs $(R T)$ when place $B$ is not called is

$$
R T=k_{0} \cdot \Delta T
$$

If the share of trips the vessel calls at place $\mathrm{B}$ is $\alpha$, expected reduction in every traveller's time costs $(E R T)$ between place $A$ and place $C$ with a change from an FS to an RS at place $B$ is

$$
E R T=k_{0} \cdot(1-\alpha) \cdot \Delta T
$$

When $\alpha$ tends to zero (one), ERT tends to $k_{0} \cdot \Delta T(0)$. The welfare consequences for travellers between place $\mathrm{A}$ and place $\mathrm{C}$ are illustrated in Figure 3. The demand curve, $D(G)$, shows the relationship between the number of travellers $(Y)$ between place $\mathrm{A}$ and place $\mathrm{C}$ and each traveller's generalised travel costs $(G){ }^{4}$ When place B has an FS, the generalised travel costs between place A and place $C$ is $G_{0}$, and the number of travellers is $Y_{0}$. When place $B$ receives an RS instead of an FS, expected generalised travel costs are reduced by $E R T$ and result in generalised costs $G_{1}$ and $Y_{1}$ to passengers. Thus, the expected benefits for travellers between place $\mathrm{A}$ and place $\mathrm{C}$ by introducing an $\mathrm{RS}$ at place $\mathrm{B}\left(W_{A C}\right)$ are equal to the shaded area in Figure 3. In Figure 3, we easily observe that $W_{A C}$ increases the more elastic demand between $\mathrm{A}$ and $\mathrm{C}$ with respect to $G$, that is, the less steep the demand curve. When the demand is completely inelastic, $W_{A C}=E R T \cdot Y_{0}$, that is, equal to the reduction in expected time costs for these travellers when B has an FS. Moreover, $W_{A C}$ increases when the demand curve shifts to the right due to the higher traffic potential between place $A$ and place $C$. This result is illustrated by the dotted demand curve $D(G)^{\prime}$.

The welfare gain estimated in Figure 3 for travellers between place $A$ and place $C$ with an RS instead of an FS at place $\mathrm{B}$ is based on the assumption that travellers between place $\mathrm{A}$ and place $\mathrm{C}$ do not care about the increased travel time variability between place $\mathrm{A}$ and place $\mathrm{C}$ caused by this schedule change. If they do not have fixed appointments at the destinations, they can use the time in an equally efficient manner independent of arrival times. However, this situation is seldom the case; the travellers normally have appointments at destinations $\mathrm{A}$ and $\mathrm{C}$ of various importance, which increase

\footnotetext{
${ }^{4}$ Generalised travel costs are the sum of the ticket price and the time costs [3]. We reasonably assume that the ticket price for those travelling between place $\mathrm{A}$ and place $\mathrm{C}$ is unchanged, regardless of whether place $\mathrm{B}$ is called. Then, the reduction in generalised travel costs for each traveller between place $\mathrm{A}$ and place $\mathrm{C}$, when there is no call at place $\mathrm{B}$, equals the reduction in expected time costs, that is, equal to $E R T$.
} 


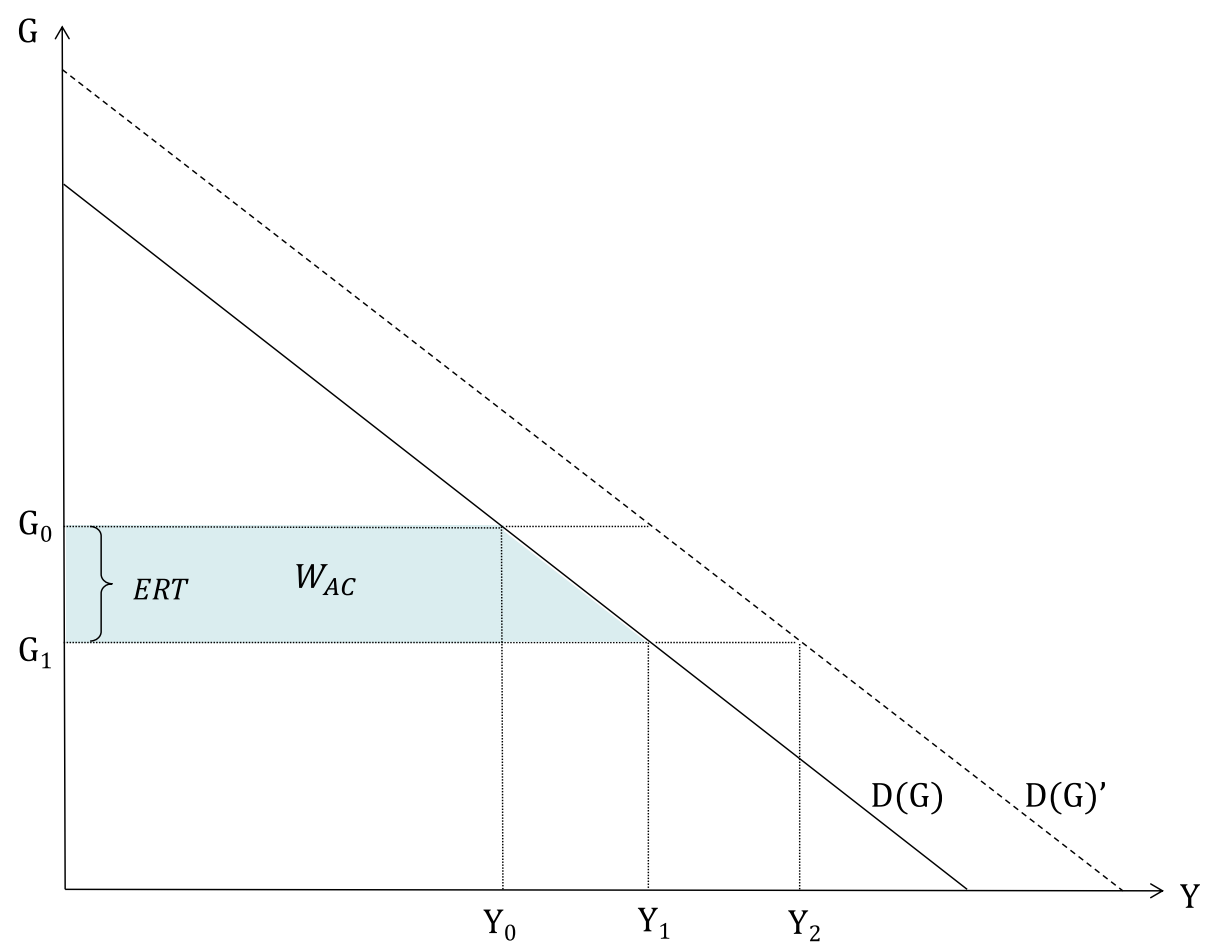

Fig. 3 Welfare changes for travellers between place $A$ and place $C$ by introducing a request stop instead of a fixed stop at place $B$

their unwillingness to make any appointments at $\mathrm{A}$ and $C$ before the arrival times when place $B$ is called.

This situation is illustrated in Figure 4 for a journey from place A to place $\mathrm{C}$ that starts at time $t_{0}$. We let $t_{1}$ and $t_{2}$ be the arrival time at place $C$ when $\mathrm{B}$ is called and not called, respectively. If an appointment is made before time $t_{1}$, the probability of not reaching the appointment is $(100 \cdot \alpha)$ percent. With fixed calls at place $\mathrm{B}$, the vessel is thus always calling place $\mathrm{C}$ at the time $t_{1}$. When place $\mathrm{B}$ receives an RS, $\Delta T=t_{1}-t_{2}=T_{0}-T_{1}$ illustrates the time span of the arrival time at place C. Expected arrival time $(E t)$ is

$$
E t=\alpha t_{1}+(1-\alpha) t_{2}
$$

Hence, $E t$ is between $t_{2}$ and $t_{1}$ (Figure 4). It follows from Eq. (4.5) that $E t$ tends to $t_{1}$ when $\alpha$ tends to 1 . If no appointments are made before $t_{1}$, the expected hidden waiting time $(E H T)$ at place $\mathrm{C}$ is

$$
E H T=t_{1}-\left[\alpha t_{1}+(1-\alpha) t_{2}\right]=(1-\alpha)\left(t_{1}-t_{2}\right)=(1-\alpha) \cdot \Delta T
$$

Benefits for travellers from place A when place B is not called thus critically depend on the difference in time value per hour when on vessel $\left(k_{0}\right)$ compared with their time value per hour $\left(k_{1}\right)$ during the time span (hidden waiting time) $E H T$. A common assumption is that $k_{0}>k_{1}$ [19]. Consequently, the expected reductions in travellers' time costs (ETK) from the departure from place A until they can start their errands at place $C$ are

$$
E T K=\left(k_{0}-k_{1}\right) \cdot E H T
$$

In summary, the benefits for the travellers between place $\mathrm{A}$ and place $\mathrm{C}\left(W_{A C}\right)$ with an $\mathrm{RS}$ at place $\mathrm{B}$ increase:

- The larger reduction in travel time $(\Delta T)$ they receive when place B is not called.

- The smaller share of the trips $(\alpha)$ between place A and place $C$ that call at place $B$.

- More passengers travelling between place A and place $\mathrm{C}\left(Y_{0}\right)$.

- The higher the difference between travellers' time values per hour when on the vessel and during their hidden waiting time $\left(k_{0}-k_{1}\right)$.

$W_{A C}$ in Figure 3 provides a satisfactory picture of the benefits for the travellers between place A and place $C$ when they can start their errands at the destinations directly after the vessel has arrived. Thus, $k_{1}=0 . W_{A C}$ thus denotes the maximum benefits for them. By contrast, if they as well could have stayed on the vessel during the time span between $t_{2}$ and $t_{1}\left(k_{1} \approx k_{0}\right)$, the benefits to them approach zero. 


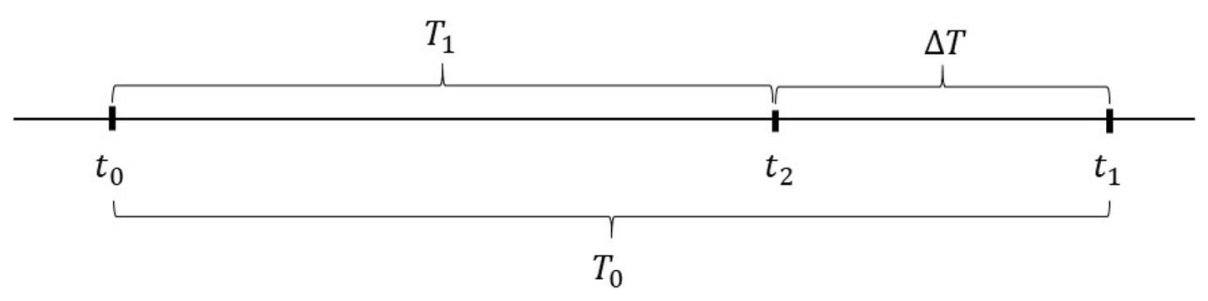

Fig. 4 Arrival times before and after place B receives an RS

\subsubsection{Empirical estimations of the consequences}

The welfare consequences for people living at place A and place $\mathrm{C}$, with an RS at place $\mathrm{B}\left(W_{A C}\right)$, can be estimated. When the number of travellers between place A and place $C\left(Y_{0}\right)$ and their generalised travel costs $\left(G_{0}\right)$ with an FS at place B are known, we can infer an approximate estimate of the shaded area in Figure 3 by calculating changes in expected generalised travel costs $\left(G_{0}\right.$ $-G_{1}$ ) and by setting a value of the travellers generalised cost elasticity. ${ }^{5}$ These calculations can be performed before the change. Another option is to ask a representative sample of travellers between place $A$ and place $C$ about their maximum willingness to pay for an RS at place $B$. The methodological challenges are the same as when asking the population at place B about their willingness to pay for FS.

\subsection{The service provider}

Four factors affect the shipping company's profit when there are RSs instead of an FS at place B. First, the revenue from travellers to/from place $B$ decreases. If these passengers pay an average fare equal to $P_{0}$, the reduction in revenues are $P_{0} \cdot\left(X_{0}-X_{1}\right)$ (Figure 2). Second, revenues increase due to a higher demand for trips between place $A$ and place $C$. If the average fare for travellers between place $\mathrm{A}$ and place $\mathrm{C}$ is $\bar{P}$, this revenue increase is $\bar{P} \cdot\left(Y_{1}-Y_{0}\right)$. Third, the operating costs for the service provider decrease because of a reduction in calls at place $\mathrm{B}$. If the cost reduction is $\Delta C$ per call and the vessel sails $N$ trips between place A and place $C$ per year, annual cost reduction is $(1-\alpha) \cdot N \cdot \Delta C$, where $(1-\alpha) \cdot N$ is the expected reduction in the number of calls at place $B$. Furthermore, there can be a reduction in grants from the transport authorities of $\left(-W_{T A}\right)$. The economic effects on the shipping company $\left(W_{S}\right)$ are summarised in Table 1.

The size of the cost reductions the service provider will receive with an RS instead of an FS at place B, depends on the frequency $(N)$ between place A and place $\mathrm{C}$, the share of trips $(\alpha)$ where the vessel calls at place B,

\footnotetext{
${ }^{5}$ We deduce that $W_{A C}=\frac{G_{0} \cdot Y_{0}}{2 \cdot \varepsilon_{G_{0}}}$, where $\varepsilon_{G_{0}}$ is the demand elasticity with respect to generalised travel costs [see [17, 34] for further discussions].
}

and the cost reduction $(\Delta C)$ each time the vessel omits calls at place B. $\Delta C$ mostly represents reduced costs for fuel and thereby depends on the reduced sailing distance by omitting calls at place $B$. Whether a reduction in grants occurs when an RS is introduced at place B depends on the contract form between the service provider and the transport authority [14, 36]. However, in the long run (next contract period), we reasonably assume a reduction in grants, implying that $W_{T A}>0$.

\subsection{Transport authorities}

The interrelationship between $W_{S}$ and $W_{T A}$ deserves further comment. If a change from an FS to an RS does not influence the authorities' grant payments to the operator, $W_{T A}=0$. Hence, if the company's revenues are less (more) reduced than the reduction in its costs, $W_{S}>0(<0)$. When the transport authorities reduce the grants so that the service provider's profit including grants remains constant, $W_{S}=0$, whereas $W_{T A}>0$. Providing that the change from an FS to an RS implies that the operator's profit before grants $(\pi)$ increases with $\Delta \pi$, the increased profit will normally be distributed between the operator and the authorities, that is, $\Delta \pi=W_{S}+W_{T A}$. When the operator only places weight on profit and the authorities only place weight on subsidy requirements and $W_{S}, W_{T A}>$ 0 , no disagreements occur between the two parties concerning the transition from an FS to an RS at place B. The exact values of the $\frac{W_{S}}{\pi}$ and the $\frac{W_{T A}}{\pi}$ ratios depend partly on the regulation regime and partly on the negotiating power between the two parties [12].

With a pure gross cost contract, the transport authority experiences a net revenue change corresponding to

Table 1 Economic effects on the shipping company

\begin{tabular}{ll}
\hline 1) Reduced revenues to/from place $B:$ & $P_{0} \cdot\left(X_{0}-X_{1}\right)$ \\
2) Increased revenues between place $A$ and place $C:$ & $\bar{P} \cdot\left(Y_{1}-Y_{0}\right)$ \\
3) Reduction in operating costs: & $(1-a) \cdot N \cdot \Delta C$ \\
4) Reduction in grants: & $W_{T A}$ \\
5) Change in profit before grants: & $\Delta T=2+3-1$ \\
6) Change in profit after grants: & $W_{S}=2+3-1-4$ \\
\hline
\end{tabular}


1) +2) (Table 1). The reduced operating cost 3) entirely passes on to the service provider. With a pure net cost contract, the transport authorities experience no change in subsidy requirements because the service provider is responsible for revenues and operating costs. Whether a tendering contract influences the authorities' budget depends on the contracts' statement about the distribution of revenue and cost changes between the parties. Consequently, the change in $W_{T A}$ and $W_{S}$ strongly depends on the risk profile in the tendering contract.

\subsection{Several request stops}

Quite a few boat routes in Norway have more than one RS between the FSs. The reason for the impacts of such cases is nearly the same as for the simple case with one RS. In the following, we therefore briefly focus on the consequences for the travellers between the fixed destinations $\mathrm{A}$ and $\mathrm{C}$.

We suppose there are $B_{1}, B_{2}, \cdots B_{M}$ places between place $A$ and place $C$ that initially have FSs and where the authorities are considering RSs at all these $M$ places. Moreover, we let $\alpha_{i}$ be the share of trips the boat calls at $B_{i}$ with an RS and $\Delta T_{i}$ be the extra travel time between place $\mathrm{A}$ and place $\mathrm{C}$ caused by calling place $B_{i}$. If we make two simple assumptions, that is, (1) the probability of calling on place $i$ is independent of whether other RSs are called and (2) the extra time of calling place $i$ is independent of whether other RSs are called ${ }^{6}$, the expected reduction in travel time $(E T)$ between place $\mathrm{A}$ and place $\mathrm{C}$ is

$$
E T=\sum_{i=1}^{M}\left(1-\alpha_{i}\right) \cdot \Delta T_{i}
$$

Thus, when the passengers travel from place $\mathrm{A}$ to place $\mathrm{C}$ and $t^{*}$ denotes the arrival time at place $\mathrm{C}$ with FSs at all B's, the expected arrival time at place C $(E t)$ when the B's receive RSs is

$$
E t=t^{*}-E T
$$

The expected hidden waiting time $(E H T)$ at place $\mathrm{C}$ is.

$$
E H T=t^{*}-E t=t^{*}-\left(t^{*}-E T\right)=E T
$$

which is exactly equal to the expected reduction in travel time between place $A$ and place $C$. If we continue to assume that the hidden waiting time cost per hour is $k_{1}$, the expected reduction in travellers' time costs (ETK) when travelling from place $\mathrm{A}$ and until they can start their errands at place B is

\footnotetext{
${ }^{6}$ The second assumption is reasonable. The first assumption is debatable because calling another request stop increases the probability that the vessel must call other request stops.
}

$$
E T K=\left(k_{0}-k_{1}\right) \cdot E T=\left(k_{0}-k_{1}\right) \cdot \sum_{i=1}^{M}\left(1-\alpha_{i}\right) \cdot \Delta T_{i}
$$

We observe from Eq. (4.11) that ETK increases to $\left(k_{0}\right.$. $E T)$ if the passengers are flexible and can spend their hidden waiting time efficiently when they arrive at place $\mathrm{C}\left(k_{1}=0\right)$. Because $\alpha_{i} \geq 0$ and $\Delta T_{i}>0$, it follows from Eq. (4.11) that the expected hidden waiting time at place $C$ increases with the number of requests stops between place A and place C. Consequently, the benefits for those travellers between place $\mathrm{A}$ and place $\mathrm{C}$ become more dependent on their abilities and possibilities to plan their stays at the destinations in a manner that makes all their time spent there meaningful.

\section{Application of the theoretical approach}

A fast craft service initially connects places A, B, and C with an FS (Figure 1). The authorities will replace the FS with an RS at place B. We assume that there are no transport options other than the fast craft service to/ from place B. Based on information on the

- number of passengers travelling to/from the three places,

- passengers' average time values,

- ticket prices to/from the three places,

- reduction in travel time between $\mathrm{A}$ and $\mathrm{C}$ when $\mathrm{B}$ is not called,

- cost savings for the operator of omitting a call at place $B$,

- frequency of the service, and

- tendering contract between the authorities and the service provider,

we can calculate the welfare consequences for the four groups involved. The parameter values in the example are listed in Table 2, together with a reference to the relevant formulas, tables, and figures.

Based on the numbers in Table 2, we calculate the welfare economic consequences of implementing an RS at place B (Table 3).

The example shows an annual increase in social surplus of $€ 58,250$ when place $B$ receives an RS instead of an FS. Because both $W$ and $W_{S}$ are positive, the shipping company's preferences are in line with what is economically profitable for society. The results in Table 3 in combination with formula (3.2) imply that the authorities must, on average, put almost a 20 times higher value on the welfare consequences for the residents of place B if place B should continue to have an FS, that is , $W^{\prime \prime}<0$. This finding implies a welfare loss of $€ 58,250$.

The aforementioned calculations are critically dependent on the proportion of times (the $a$-value) the vessel must call on place B. If, for example, $a$ increases from 0.6 to 0.9 and $W_{B}$ is unchanged, $W_{A C}, W_{S}$, and 
Table 2 Parameter values used in the calculation example with comments

\begin{tabular}{|c|c|c|c|}
\hline $\begin{array}{l}\text { Fig./ Eq./ } \\
\text { Table }\end{array}$ & Parameter & Value & Comment \\
\hline Eq. 4.1 & $x_{0}$ & 1000 & $\begin{array}{l}\text { Average number of passengers per year travelling to/from place B before an RS was implemented. The number is } \\
\text { representative of a typical Norwegian fast craft service. }\end{array}$ \\
\hline Eq. 4.1 & $x_{1}$ & 950 & $\begin{array}{l}\text { Average number of passengers travelling to/from place B after an RS is implemented. This number can be } \\
\text { calculated by referring to the pre-booking procedures, experiences from services that previously have converted } \\
\text { calls from an FS to an RS, or by simply asking inhabitants at the actual place about their expected change in travel } \\
\text { behaviour. }\end{array}$ \\
\hline Figure 2 & $P_{0}$ & $€ 15$ & $\begin{array}{l}\text { The ticket price for those travelling to/from place B can be found from the fare tariff. An average travel distance on } \\
\text { fast craft services in Norway is approximately } 30 \mathrm{~km} \text {. In 2019, the fare for an adult for this distance was } \\
\text { approximately } € 15 \text {. }\end{array}$ \\
\hline Table 2 & $\bar{P}$ & $€ 20$ & $\begin{array}{l}\text { Ticket price for those travelling between } A \text { and } C \text {. Because we assume that the distance } A-C \text { is longer than } A-B \text { and } \\
B-C \text {, we presume } \bar{P}>P_{0} \text {. }\end{array}$ \\
\hline Eq. 4.1 & $W_{B}$ & $\begin{array}{l}€- \\
3000\end{array}$ & $\begin{array}{l}\text { The welfare change for the inhabitants at place B when place B receives an RS instead of an FS. The loss can be } \\
\text { calculated by, e.g. a survey among the inhabitants on their willingness to pay for not losing the FS. }\end{array}$ \\
\hline Figure 3 & $Y_{0}$ & 10,000 & Average number of passengers per year travelling between $A$ and $C$ when $B$ has an FS. \\
\hline Figure 3 & $Y_{1}$ & 11,000 & $\begin{array}{l}\text { Average number of passengers per year travelling between } \mathrm{A} \text { and } \mathrm{C} \text { after an } \mathrm{RS} \text { is implemented at place } \mathrm{B} \text {. This } \\
\text { number can be calculated by estimating expected reduction in generalised travel costs per passenger and } \\
\text { subsequently calculating the increase in the number of trips by using a generalised cost elasticity. }\end{array}$ \\
\hline Eq. 4.2 & $\Delta T$ & $0.25 \mathrm{~h}$ & $\begin{array}{l}\text { The time savings for passengers between } \mathrm{A} \text { and } \mathrm{C} \text { by omitting a call at place } \mathrm{B} \text {. These savings can be calculated by } \\
\text { the service provider based on the deviation from the main fairway and for a representative terminal time at the call. }\end{array}$ \\
\hline Eq. 4.3 & $k_{0}$ & $€ 8$ & $\begin{array}{l}\text { Average time value per hour for fast craft passengers can be derived from a travel survey on the current route. } \\
\text { Notably, €8 is a proxy for the average time value per passenger used in the cost-benefit analysis in Norway in } 2019 .\end{array}$ \\
\hline Eq. 4.4 & $a$ & 0.60 & $\begin{array}{l}\text { Proportion of times people travelled to/from place B before an RS was implemented. The value of a can be found } \\
\text { from historical data on the travel activity. }\end{array}$ \\
\hline Table 2 & $N$ & 700 & $\begin{array}{l}\text { Annual number of trips offered between } A \text { and } C \text {. This number is found in the time table for the service in } \\
\text { question. Our example is based on a service with a daily round trip. }\end{array}$ \\
\hline Table 2 & $\Delta C$ & $€ 200$ & $\begin{array}{l}\text { Cost savings for the service provider per trip by not calling place B. It is primarily reduced fuel costs and quay/ } \\
\text { terminal costs. The value used is related to a call that increases the travel time between } A \text { and } C \text { by } 0.25 \mathrm{~h} \text {. }\end{array}$ \\
\hline Table 2 & $W_{T A}$ & $\begin{array}{l}€ 28, \\
000\end{array}$ & $\begin{array}{l}\text { This number can be calculated based on the contract form. We assume that the contract says that } 50 \% \text { of the cost } \\
\text { reduction shall go to the service operator (Table } 3 \text { ). }\end{array}$ \\
\hline
\end{tabular}

$W_{T A}$ decrease to $€ 2100, € 26,250$, and $€ 1400$, respectively. This finding implies that $W=€ 26,750$. Consequently, the positive welfare effects of replacing an FS with an RS at place $B$ are significantly reduced.

Notably, we disregard that travellers between place $A$ and $C$ have increased uncertainty in travel time with an RS at place B. Consequently, we overestimate the positive effects of an RS at place B for these travellers because we tacitly assume that their time value $\left(k_{1}\right)$ during the hidden waiting time is zero; see Eq. (4.7).

\section{Summary and concluding remarks}

In this paper, we have discussed welfare and distributional consequences of an RS instead of an FS, exemplified by a fast craft route serving place $A-B-C$, where place $\mathrm{B}$ receives an $\mathrm{RS}$. Welfare economic effects $(W)$ are related to the residents of place $\mathrm{B}\left(W_{B}\right)$, those

Table 3 Annual welfare consequences for the involved groups

\begin{tabular}{|c|c|c|c|}
\hline Welfare component & Description & Value $(€)$ & Calculations \\
\hline$\overline{W_{A C}}$ & Welfare increase for the travellers between $\mathrm{A}$ and $\mathrm{C}$ & 8400 & $\begin{array}{l}\text { Existing trips: }[(0.25 \cdot 8) \cdot(1-0.6) \cdot 10,000]=8,000 \\
\text { New trips: }[(0.25 \cdot 8) \cdot(1-0.6) \cdot(11,000-10,000] \cdot 1 / 2=400 \\
\text { Sum: } 8,400\end{array}$ \\
\hline$W_{B}$ & Welfare changes for the residents at place $B$ & -3000 & Based on a 'willingness to pay survey'. \\
\hline$W_{S}$ & Increased profit for the service operator & 47,250 & $\begin{array}{l}\text { Reduced revenues to/from B: }[15 \cdot(1,000-950)]=-750 \\
\text { Increased revenues A-C: }[20 \cdot(11,000-10,000)]=20,000 \\
\text { Reduced operating costs: }[(1-0.6) \cdot 700 \cdot 200]=56,000 \\
\text { Reduced grants: }(56,000 \cdot 0,5)=-28,000 \\
\text { Sum: } 47,250\end{array}$ \\
\hline$W_{T A}$ & Welfare effect of reduced payments of grants & 5600 & Contract formulation and $\gamma=0.20:(56,000 \cdot 0.5 \cdot 0.20)=5,600$ \\
\hline W & Sum of welfare consequences & 58,250 & Sum of welfare consequences for all groups. \\
\hline
\end{tabular}


travelling between place $\mathrm{A}$ and place $\mathrm{C}\left(W_{A C}\right)$, the service provider $\left(W_{S}\right)$, and the transport authorities $\left(W_{T A}\right)$. The unweighted sum of the effects on all parties is the total welfare economic effects $(W)$ of implementing an RS at place B. If $W>0$, an RS is desirable from a welfare perspective. However, due to regional policy goals, decision makers may place unequal weights on the welfare for the four mentioned groups. Consequently, the value of $W$ and the weighted sum $\left(W^{\prime \prime}\right)$ can have different signs. If $W^{*}<0$ and $W>0$, the political weights put on the welfare of the four groups imply that an RS at place B will not be implemented, although this implementation would have increased social welfare by $W$. The welfare effects of an RS can be summarised as follows:

- Travellers to/from place B experience a welfare loss, implying $W_{B}<0$. The higher the traffic to/from the place and the longer time ahead passengers must pre-book a trip, the larger the disadvantages. Use of digital pre-booking platforms and other transport possibilities to/from place $B$ reduce the disadvantages.

- Travellers between place $\mathrm{A}$ and place $\mathrm{C}$ experience a welfare gain $\left(W_{A C}>0\right)$. Its magnitude increases with the amount of traffic between these two places, the passengers' travel time values, and the more sensitive demand with respect to generalised travel costs. Moreover, $W_{A C}$ increases the fewer share of the trips the vessel must call on at place $B$ and the more flexible plans the passengers can make at destinations A and C. ${ }^{7}$ Last, good mobile signal coverage along the route further strengthens these advantages because of the possibilities passengers have to inform others about the vessel's expected arrival time. Real-time information systems generate similar benefits.

- The service provider experiences a reduction in revenues to/from place $\mathrm{B}$, increased revenues to/ from place $A$ and place $C$, and reduced operating costs. If the net effects of these changes imply lower subsidy needs for the service provider, neither the operator nor the authorities would normally be worse off when $\mathrm{B}$ receives an RS. Thus, $W_{S}, W_{T A} \geq$ 0 . The risk sharing in the tendering contract between them is crucial to how the potential decrease in subsidy needs is distributed.

Finally, and notably, the benefits of implementing an RS at place B strongly depend on how often the vessel

\footnotetext{
${ }^{7}$ A positive correlation between reduced travel time for travellers between place $A$ and place $C(\Delta T)$ and reduced operating costs for the service provider of the RS at place $B(\Delta C)$. Due to reduced sailing distance, $\Delta T$ and $\Delta C$ decrease when the vessel can drop calls at place B.
}

still must call on place B. If, for example, if place B must be called on for more than $95 \%$ of the trips, an RS can be directly disadvantageous; the inhabitants at place $\mathrm{B}$ still have the inconvenience of pre-booking calls, and passengers that travel between place $\mathrm{A}$ and place $\mathrm{C}$ receive an insignificant reduction in expected travel time. Simultaneously, their travel time becomes more uncertain. The proportion of trips to place $B$ that must be called with an RS is thus more important for the outcome than annual traffic to/from place B. This result implies that decision makers should increase their emphasis on the distribution of traffic throughout the week rather than the sum of yearly traffic.

The pure commercial savings of having an RS at a place instead of an FS, the value of $\Delta \pi$, are possible to estimate quite accurately. However, measuring the monetary impacts on the different affected groups involved is far more difficult. In addition to calculations using Eq. (3.1), decisions regarding route changes should be based on sound judgements, thorough knowledge of traffic patterns, and local conditions at the actual port of calls along the route. Implementing an RS instead of an FS is a question that will increase in relevance in the forthcoming years because of changes in the settlement pattern. Further empirical studies should more precisely evaluate the effects of such measures to overcome the limitations of this study.

\section{Acknowledgements}

Not applicable.

\section{Authors' contributions}

The authors have contributed equally to the writing of the article. The author(s) read and approved the final manuscript.

\section{Funding}

Not applicable.

\section{Availability of data and materials}

Not applicable.

\section{Competing interests}

The authors declare that they have no competing interests.

Received: 20 November 2019 Accepted: 29 April 2020

Published online: 11 May 2020

\section{References}

1. Brake, J., \& Nelson, J. D. (2007). A case study of flexible solutions to transport demand in a deregulated environment. Journal of Transport Geography, 15, 262-273.

2. Brake, J., Nelson, J. D., \& Wright, S. (2004). Demand responsive transport: Towards the emergence of a new market segment. Journal of Transport Geography, 12, 323-337.

3. Button, K. (2010). Transport economics, 3rd Edition. Cheltenham, UK: Edward Elgar.

4. Carotenuto, P., \& Martis, F. (2017). A double dynamic fast algorithm to solve multi-vehicle dial a ride problem. Transportation Research Procedia, 27, 632-639.

5. Carotenuto, P., Paradisi, L. and Storchi, G. (2014). A Flexible Transport Service for Passengers. 17th Meeting of the EURO Working Group on Transportation, EWGT2014, 2-4 July 2014, Sevilla, Spain. Transportation Research Procedia 3 (2014), 442-451. 
6. Cordeau, J.-F., \& Laporte, G. (2007). The dial-a-ride problem: Models and algorithms. Annals of Operations Research, 153(1), 29-46.

7. Davison, L., Enoch, M., Ryley, T., Quddus, M., \& Wang, C. (2014). A survey of demand responsive transport in Great Britain. Transport Policy, 31, 47-54.

8. Diana, M., Quadrifoglio, L., \& Pronello, C. (2007). Emissions of demand responsive services as an alternative to conventional transit systems. Transportation Research Part D, 12, 183-188.

9. Furth, P. G., \& Muller, T. H. J. (2009). Optimality conditions for public transport schedules with timepoint holding. Public Transp, 1, 87-102

10. Gomes, R., de Sousa, J. P., \& Dias, T. G. (2015). Sustainable demand responsive transportation systems in a context of austerity: The case of a Portuguese city. Research in Transportation Economics, 51, 94-103.

11. Goodwin, P. B. (1993). Car ownership and public transport use: Revisiting the interaction. Transportation, 27, 21-33.

12. Hensher, D. A., Ho, C., \& Knowles, L. (2016). Efficient contracting and incentive agreements between regulators and bus operators: The influence of risk preferences of contracting agents on contract choice. Transportation Research Part A, 87, 22-40.

13. Hensher, D. A., Rose, J. M. and Green, W. H. (2005). Applied choice analysis A Primer. Cambridge University press.

14. Hensher, D. A., \& Stanley, J. (2008). Transacting under a performance-based contract: The role of negotiation and competitive tendering. Transportation Research Part A, 42, 1143-1151.

15. Ho, S. C., Szeto, W. Y., Kuo, Y.-H., Leung, J. M. Y., Petering, M., \& Tou, T. W. H. (2018). A survey of dial-a-ride problems: Literature review and recent developments. Transportation Research Part B, 111, 395-421.

16. Jain, S., Ronald, N., Thompson, R., \& Winter, S. (2017). Predicting susceptibility to use demand responsive transport using demographic and trip characteristics of the population. Travel Behaviour and Society, 6, 44-56.

17. Jørgensen, F., Mathisen, T. A., \& Larsen, B. (2011). Evaluating transport user benefits and social surplus in a transport market-the case of the Norwegian ferries. Transport Policy, 18, 76-84.

18. Jørgensen, F., Mathisen, T. A. and Solvoll, G. (2008). Hurtigbåttillbudet i Nordland Rutestandard og økonomi. (fast craft services in Nordland - Service quality and economy. In Norwegian). SIB-rapport nr. 3 2008. Handelshøgskolen i Bodø.

19. Jørgensen, F., \& Solvoll, G. (2018). Determining optimal frequency at ferry crossings. Transport Policy, 63, 215-223.

20. Kim, M. E., \& Schonfeld, P. (2015). Maximizing net benefits for conventional and flexible bus services. Transportation Research Part A, 80, 116-133.

21. Koffman, D. (2004). Operational experiences with flexible transit services. A Synthesis of Transit Practice. Transportation Research Board. Washington D.C.

22. Mageean, J., \& Nelson, J. D. (2003). The evaluation of demand responsive transport services in Europe. Journal of Transport Geography, 11, 255-270.

23. Makridakis, S., Wheelwright, S. C. and Hyndman, R. J. (1998). Forecasting. Methods and applications. John Wiley \& Sons Inc., USA.

24. Marsden, P. V. and Wright, J. D. (2010). Handbook of survey research. Second edition. Emerald.

25. Mulley, C., Nelson, J., Teal, R., Wright, S., \& Daniels, R. (2012). Barriers to implementing flexible transport services: An international comparison of the experiences in Australia, Europe and USA. Research in Transportation Business and Management, 3, 3-11.

26. Nourbakhsh, S. M., \& Ouyang, Y. (2012). A structured flexible transit system for low demand areas. Transportation Research Part B, 46, 204-216.

27. Papangelis, K., Nelson, J. D., Sripada, S., \& Beecroft, M. (2016). The effects of mobile real-time information on rural passengers. Transportation Planning and Technology, 39(1), 97-114.

28. Parragh, S. N., Doerner, K. F.,Hartl, R. F. (2008). A survey on pickup and delivery problems. Part II: Transportation between pickup and delivery location. Journal für Betriebswirtschaft Vol 58 (2), 81-117.

29. Pindyck, R. S. and Rubinfeld, D. L. (2013). Microeconomics. Eight edition. Pearson.

30. Qiu, F., Shen, J., Zhang, X., \& An, C. (2015). Demi-flexible operating policies to promote the performance of public transit in low-demand areas. Transportation Research Part A, 80, 215-230.

31. Rodier, C. J., Johnston, R. A., \& Shabazian, D. R. (1998). Evaluation of advanced transit alternatives using consumer welfare. Transportation Research Part C, 6, 141-156.

32. Ryley, T. J., Stanley, P. A., Enoch, M. P., Zanni, A. M., \& Quddus, M. A. (2014). Investigating the contribution of demand responsive transport to a sustainable local public transport system. Research in Transportation Economics, 48, 364-372.

33. Saeed, K., \& Kurauchi, F. (2015). Enhancing the service quality of transit systems in rural areas by flexible transport services. 18th Euro working group on transportation, EWGT 2015, 14-16 July 2015, Delft, the Netherlands. Transportation Research Procedia, 10, 514-523.

34. Solvoll, G., \& Hanssen, T.-E. S. (2018). Importance of aviation in higher education. Journal of Air Transport Management, 72, 47-55.

35. Velaga, N. R., Nelson, J. D., Wright, S. D., \& Farrington, J. H. (2012). The potential role of flexible transport Services in Enhancing Rural Public Transport Provision. Journal of Public Transportation, 15(1), 111-131.

36. Wallis, I., Bray, D., \& Webster, H. (2010). To competitively tender or to negotiate - weighing up the choices in a mature market. Research in Transportation Economics, 29, 89-98.

37. Wang, C., Quddus, M., Enoch, M., Ryley, T., \& Davison, L. (2015). Exploring the propensity to travel by demand responsive transport in the rural area of Lincolnshire in England. Case Studies on Transport Policy, 3, 129-136.

38. Watkins, K. E., Ferris, B., Rutherford, G. S. and Layton, D. (2011). Where is my bus? Impact of mobile real-time information on the perceived and actual wait time of transit riders Transportation Research Part A 45, 839-848.

\section{Publisher's Note}

Springer Nature remains neutral with regard to jurisdictional claims in published maps and institutional affiliations.

\section{Submit your manuscript to a SpringerOpen ${ }^{\circ}$ journal and benefit from:}

- Convenient online submission

- Rigorous peer review

- Open access: articles freely available online

- High visibility within the field

- Retaining the copyright to your article

Submit your next manuscript at $>$ springeropen.com 